\title{
Effect of compression garments on delayed-onset muscle soreness and blood inflammatory markers after eccentric exercise: a randomized controlled trial
}

\author{
Jieun Kim, Jooyoung Kim, Joohyung Lee* \\ Health and Rehabilitation Major, Kookmin University, Seoul, Korea
}

The purpose of this study was to investigate how compression garments, applied after eccentric exercise, can affect delayed onset muscle soreness (DOMS) and inflammatory markers. Sixteen healthy male university students enrolled in this study and were randomly assigned to either the compression garment group (CG, $n=8$ ) or control group (CON, $n=8$ ). All participants performed two sets of eccentric exercise using elbow flexor with 25 repetitions per set on a modified preacher curl machine. Maximal isometric strength was measured before exercise and immediately, 24, 48, 72, and $96 \mathrm{hr}$ after eccentric exercise. Muscle soreness was measured before exercise and 24, 48, 72, and 96 hr after eccentric exercise. Creatine kinase (CK) activity and tumor necrosis factor-alpha (TNF- $\alpha$ ) levels were also measured before exercise and 3, 6, 24, and $48 \mathrm{hr}$ after exercise. A repeated measures analysis of variance was used for statistical analysis. The CG group reported faster recovery of maximal isometric strength following exercise $(P<0.001)$ and lower muscle soreness during the recovery period than the control group $(P<0.05)$. However, there were no significant differences in either CK activity or TNF- $\alpha$ levels between the two groups $(P>0.05)$. In conclusion, wearing compression garments during the postexercise period can be an effective way to reduce DOMS and accelerate the recovery of muscle function.

Keywords: Compression garments, Delayed-onset muscle soreness, Eccentric exercise, Inflammatory response

\section{INTRODUCTION}

High-intensity eccentric exercise can cause muscle damage, if the exercise is repeated (Fulford et al., 2015). Delayed-onset muscle soreness (DOMS) is the most common symptom of exercise-induced muscle damage (Lieber and Friden, 2002). In general, DOMS occurs between 24-48 hr after exercise and eventually induces a reduction in muscle function and range of motion with a concomitant increase in creatine kinase $(\mathrm{CK})$ activity, thus causing psychological discomfort (Evans et al., 1986; Kim and Lee, 2014; Serinken et al., 2013). Several interventions are recommended for reducing DOMS, including cold-water immersion, heat, manual therapy, vibration therapy, compression garments, and nutritional supplements (Cochrane, 2017; Fonseca et al., 2016; Jakeman et al., 2010; Kim and Lee, 2014; Petrofsky et al.,
2017; Urakawa et al., 2015).

In particular, compression garments, which are mainly required for vascular pathology and plastic surgery (Berjeaut et al., 2015; Gottrand et al., 2016), are increasingly being used in sporting disciplines for the purpose of improving not only exercise performance but also postexercise recovery (Driller and Halson, 2013; Hill et al., 2014). In addition to the fact that compression garments are easy and convenient to carry, they have also been reported to be effective in relieving DOMS (Jakeman et al., 2010; Kraemer et al., 2001). For example, Kraemer et al. (2001) reported a reduction of DOMS in untrained women who wore compression garments following eccentric exercise. In another study, Jakeman et al. (2010) confirmed a reduction of DOMS in physically-active women who used compression garments following plyometric exercise and described the application of such garments as an effec-
*Corresponding author: Joohyung Lee (iD https://orcid.org/0000-0001-8279-3830 Sport, Health and Rehabilitation Major, College of Physical Education, Kookmin University, 77 Jeongneung-ro, Seongbuk-gu, Seoul 02707, Korea Tel: +82-2-910-5254, Fax: +82-2-910-4789, E-mail: jolee@kookmin.ac.kr Received: September 4, 2017 / Accepted: October 12, 2017
This is an Open Access article distributed under the terms of the Creative Commons Attribution Non-Commercial License (http://creativecommons.org/licenses/by-nc/4.0/) which permits unrestricted non-commercial use, distribution, and reproduction in any medium, provided the original work is properly cited. 
tive strategy for recovery.

Several studies have indicated inflammatory responses as a potential mechanism to explain the reduction of DOMS (Hill et al., 2014; Kraemer et al., 2001). Nonetheless, only a limited number of studies have directly measured changes in inflammatory response indicators. Given the well-established hypothesis that DOMS is caused by inflammatory response (Cheung et al., 2003; Kim and Lee, 2014; Smith, 1991), an attempt to measure DOMS and inflammatory markers could be advantageous in clarifying the effectiveness of compression garments as a postexercise recovery measure. In addition, the exercise using elbow flexor could provide new insights into the effects of compression garments on small muscles because most previous studies in this area used exercise models involving lower limb muscles. It is important to consider that muscle size is a factor that affects DOMS and inflammatory responses following muscle damage (Jamurtas et al., 2005; Peake et al., 2005).

Therefore, the aim of this study was to investigate how wearing compression garments after eccentric exercise using elbow flexor could change DOMS and inflammatory response.

\section{MATERIALS AND METHODS}

\section{Participants}

This study was conducted on 16 healthy male university students who met our specific inclusion criteria, which included no participation in any resistance exercise on a regular basis over the last 6 months, no intake of dietary supplements such as creatine, whey proteins or vitamins, taking no medication and no history of musculoskeletal diseases. All participants voluntarily provided informed written consent before enrolment study and were randomly assigned to either a compression garment group (CG, $n=8)$ or a control group (CON, $n=8)$. Characteristics of participants are given in Table 1.

\section{Eccentric exercise}

The eccentric exercise applied in this study was based on a previous study by Clarkson et al. (2005). Participants were instructed

Table 1. Characteristics of participants

\begin{tabular}{lcccc}
\hline Group & Age $(\mathrm{yr})$ & Height $(\mathrm{cm})$ & Weight $(\mathrm{kg})$ & Body fat $(\%)$ \\
\hline CON $(\mathrm{n}=8)$ & $23.13 \pm 3.76$ & $174.13 \pm 10.91$ & $75.44 \pm 12.01$ & $21.01 \pm 6.96$ \\
CG $(\mathrm{n}=8)$ & $24.25 \pm 1.28$ & $175.63 \pm 2.62$ & $74.58 \pm 10.41$ & $15.54 \pm 4.98$ \\
\hline
\end{tabular}

Values are presented as mean \pm standard deviation. No significant difference between groups.

$\mathrm{CON}$, control group; $\mathrm{CG}$, compression garments group. to place their elbow flexor on a modified preacher curl machine and execute an eccentric contraction of the muscle. Each eccentric muscle contraction was performed for $3 \mathrm{sec}$, according to signals from the investigator, followed by a 12 -sec rest period. Each participant completed two sets, performing 25 reps per set with a 5-min rest period between sets.

\section{Compression garments}

The compression sleeves applied in this study were based on those described by Kraemer et al. (2001). These arm sleeves (PRO Racing Arm Sleeve, Compressport International, S.A., Nyon, Switzerland) provided compression of 5-10 $\mathrm{mmHg}$ (Fig. 1). Before initiation of the study, the biceps muscle and wrist of all participants were measured to ensure they were fitted with the appropriate size of compression garment. As suggested by Goto and Morishima (2014), the compression sleeves were applied for $24 \mathrm{hr}$ as soon as the eccentric exercise was finished.

\section{Maximal isometric strength}

In this study, maximal isometric strength (MIS) was measured using a strain gauge (Jackson Strength Evaluation System, Model 32628CTL, Lafayette Instrument Co., Lafayette, IN, USA), which was attached to the modified preacher curl machine. With the elbow flexor positioned against the preacher bench pad, the participant started pulling the pad with maximal force, upon a signal from the investigator, and maintained each contraction for 3 sec. MIS was measured twice and a mean of the two measurements

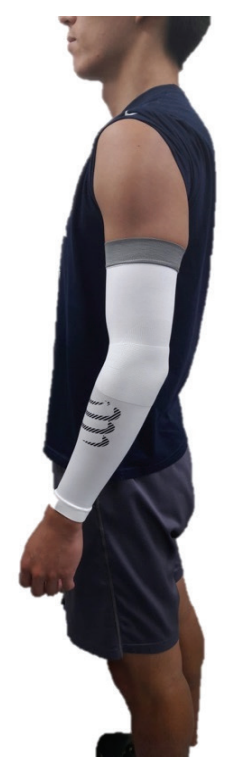

Fig. 1. Compression garment used in the study. 
Kim J, et al. • Compression garments and delayed-onset muscle soreness

Table 2. Change of maximal isometric strength after eccentric exercise (unit: \%)

\begin{tabular}{lccccccc}
\hline Group & Pre & Post & $24 \mathrm{Hr}$ & $48 \mathrm{Hr}$ & $72 \mathrm{Hr}$ & $96 \mathrm{Hr}$ & $P$-value \\
\hline CON $(n=8)$ & $100 \pm 0.0$ & $39.3 \pm 27.3$ & $33.0 \pm 26.3$ & $42.5 \pm 23.0$ & $42.7 \pm 23.6$ & $55.0 \pm 21.3$ & 0.000 \\
CG $(n=8)$ & $100 \pm 0.0$ & $57.7 \pm 16.9$ & $68.9 \pm 12.9^{* *}$ & $74.3 \pm 21.5^{*}$ & $89.4 \pm 18.7^{* *}$ & $99.8 \pm 21.0^{* *}$ & \\
\hline
\end{tabular}

Values are presented as mean \pm standard deviation.

$\mathrm{CON}$, control group; $\mathrm{CG}$, compression garments group.

${ }^{*} P<0.05$. ${ }^{* *} P<0.01$.

Table 3. Change of muscle soreness after eccentric exercise (unit: $\mathrm{mm}$ )

\begin{tabular}{lcccccc}
\hline Group & Pre & $24 \mathrm{Hr}$ & $48 \mathrm{Hr}$ & $72 \mathrm{Hr}$ & $96 \mathrm{Hr}$ & $P$-value \\
\hline CON $(n=8)$ & $0.6 \pm 1.7$ & $48.8 \pm 19.1$ & $55.6 \pm 22.9$ & $50.5 \pm 27.5$ & $37.0 \pm 21.4$ & 0.038 \\
CG $(n=8)$ & $0.6 \pm 1.7$ & $29.6 \pm 10.5^{*}$ & $36.6 \pm 19.9$ & $21.9 \pm 18.9^{*}$ & $7.4 \pm 11.8^{* *}$ & \\
\hline
\end{tabular}

Values are presented as mean \pm standard deviation.

$\mathrm{CON}$, control group; $\mathrm{CG}$, compression garments group.

${ }^{*} P<0.05$. ${ }^{* *} P<0.01$.

Table 4. Change of creatine kinase after eccentric exercise (unit: U/L)

\begin{tabular}{lcccccc}
\hline Group & Pre & $3 \mathrm{Hr}$ & $6 \mathrm{Hr}$ & $24 \mathrm{Hr}$ & $48 \mathrm{Hr}$ & $P$-value \\
\hline CON $(n=8)$ & $118.2 \pm 50.02$ & $133.0 \pm 44.5$ & $143.8 \pm 53.7$ & $217.6 \pm 146.4$ & $447.0 \pm 530.4$ & 0.554 \\
CG $(n=8)$ & $173.2 \pm 80.6$ & $178.3 \pm 76.4$ & $193.8 \pm 91.0$ & $213.0 \pm 122.5$ & $337.8 \pm 365.1$ & \\
\hline
\end{tabular}

Values are presented as mean \pm standard deviation.

$\mathrm{CON}$, control group; $\mathrm{CG}$, compression garments group.

Table 5. Change of tumor necrosis factor- $\alpha$ after eccentric exercise (unit: $\mathrm{pg} / \mathrm{mL}$ )

\begin{tabular}{lcccccc}
\hline Group & Pre & $3 \mathrm{Hr}$ & $6 \mathrm{Hr}$ & $24 \mathrm{Hr}$ & $48 \mathrm{Hr}$ & $P$-value \\
\hline CON $(n=8)$ & $0.8 \pm 0.6$ & $0.8 \pm 0.6$ & $0.5 \pm 0.4$ & $0.2 \pm 0.3$ & $0.4 \pm 0.6$ & 0.443 \\
CG $(n=8)$ & $0.4 \pm 0.2$ & $0.7 \pm 0.4$ & $0.8 \pm 0.8$ & $0.3 \pm 0.2$ & $0.3 \pm 0.2$ & \\
\hline
\end{tabular}

Values are presented as mean \pm standard deviation.

CON, control group; $\mathrm{CG}$, compression garments group.

was calculated. Measurements were taken before exercise and immediately, 24, 48, 72, and $96 \mathrm{hr}$ after exercise (Table 2).

\section{Muscle soreness}

Muscle soreness was assessed using the visual analogue scale (VAS). Participants were asked to draw a vertical line across the VAS scale to indicate the level of soreness they felt. Muscle soreness was measured before exercise and 24, 48, 72, and $96 \mathrm{hr}$ after exercise (Table 3).

\section{CK activity}

A blood sample of $3 \mathrm{~mL}$ was collected from the brachial vein to assess $\mathrm{CK}$ activity. Blood samples were centrifuged and then $\mathrm{CK}$ activity were measured using a commercial assay kit (AceChem CK Kit, YD-Diagnostics Corp., Yongin, Korea) and automated clinical chemistry analyzers (Miura One, I.S.E. S.r.l., Rome, Italy) before exercise and 3, 6, 24, and $48 \mathrm{hr}$ after exercise (Table 4).

\section{Tumor necrosis factor-alpha}

Tumor necrosis factor-alpha (TNF- $\alpha$ ) level was also assessed from the same blood samples collected from the brachial vein. TNF- $\alpha$ was analyzed using a commercial assay kit (ProcataPlex mix \& match human 2-plex, Affymetrix eBioscience, Wien, Austria) in accordance with manufacturer's instructions. The analysis was completed with a clinical diagnostics instrument (Luminex 200 System, Luminex Corp., Austin, TX, USA). TNF- $\alpha$ levels were assessed before exercise and 3, 6, 24, and $48 \mathrm{hr}$ after exercise (Table 5).

\section{Statistical analysis}

Data were analyzed using IBM SPSS Statistics ver. 21.0 (IBM Co., Armonk, NY, USA) and presented as means and standard deviations. A repeated measures analysis of variance was used to determine interactions between group and time. If an interaction was present, an independent-samples $t$-test was used to determine 
the differences between the groups at different time points. The level of significance was set at $P<0.05$.

\section{RESULTS}

\section{Maximal isometric strength}

Statistical analysis revealed significant main effects of time $(P<0.001)$, group $(P<0.01)$, and the interaction between time and group for MIS $(P<0.001)$. Specifically, the $\mathrm{CG}$ group demonstrated faster recovery than the control group between 24 and 96 hr after exercise.

\section{Muscle soreness}

There were significant main effects of time $(P<0.001)$, group $(P<0.01)$, and the interaction between time and group $(P<0.05)$ for muscle soreness. The $\mathrm{CG}$ group showed lower muscle soreness during the recovery period, compared with the control group.

\section{CK activity}

There were no significant changes in CK activity with respect to time, group and the interaction between time and group $(P>0.05)$.

\section{Tumor necrosis factor-alpha}

No significant changes were observed in TNF- $\alpha$ level with respect to time, group and the interaction between time and group $(P>0.05)$.

\section{DISCUSSION}

This study aimed to identify the effects of compression garments, applied after eccentric exercise, on DOMS and inflammatory markers. Our analysis showed that compression garments effectively reduced DOMS and helped the recovery of MIS. However, the effects of compression garments upon CK activity and TNF-a levels were not statistically significant.

These results are consistent with those reported in previous studies. For example, Goto and Morishima (2014) reported that compression garments led to lower muscle soreness and faster recovery of maximal strength after resistance exercise and that changes in CK, interleukin 6 (IL-6), interleukin 1 receptor antagonist were not significant in the intervention group, when compared with the control group. More recently, Goto et al. (2017) reported reduced muscle soreness in a compression garment group after high intensity exercise composed of repeated sprint exercise, resistance exercise and drop jumps. However, resulting changes in CK and IL-6 were not statistically significant. These findings support the possibility that inflammatory response is not associated with the reduction of DOMS induced by compression garments. Several previous studies claimed that compression garments can reduce inflammatory response (Hill et al., 2014; Kraemer et al., 2001); although these claims were not hypothesis tested. Valle et al. (2014) further reported that compression garments reduced the levels of infiltration by inflammatory cells such as lymphocytes $\mathrm{CD} 3$ + and neutrophils and helped prevent DOMS in soccer players following eccentric exercise. However, in the study by Valle et al. (2014), compression garments were applied during exercise. Thus, the application time and the exercise model are very different from those described in this current study. Hence, further studies are now required to investigate changes in inflammatory responses at the molecular or cellular levels, as carried out by Valle et al. (2014). The fact that postexercise plasma cytokine levels are affected by circulation or blood flow also supports such investigations (Hirose et al., 2004). If these issues are addressed in future studies, the association between compression garments and DOMS could be further clarified.

In this study, it is possible that the reduction of DOMS was affected by other factors in addition to the compression garments. Some previous studies reported that compression garments reduced muscle oscillation and stabilized the array of muscle fibers during the recovery period (Kraemer et al., 2001; MacRae et al., 2011). Another study pointed out that reduced muscle oscillation could ease mechanical stress on tissues (Valle et al., 2014). This particular role of compression garments appears to eventually reduce additional injuries that may occur after eccentric exercise. However, this assumption needs to be verified by appropriate experimentation. Another possibility involves potential psychological effects. Duffield and Portus (2007) suggested that psychological recovery, as promoted by the application of a compression garment, triggered reduced levels of muscle soreness which occurred 24-hr postexercise.

Overall, the use of compression garments for $24 \mathrm{hr}$ following eccentric exercise reduced DOMS and accelerated the recovery of muscle function, but failed to influence the levels of key inflammatory markers. These results provide evidence that compression garments are effective in promoting postexercise recovery, thus highlighting the fact that compression garments are useful tools for sport-related individuals including coaches, trainers, and athletes who perform high-intensity exercise repeatedly. 


\section{CONFLICT OF INTEREST}

No potential conflict of interest relevant to this article was reported.

\section{REFERENCES}

Berjeaut RH, Nahas FX, Dos Santos LK, Filho JD, Ferreira LM. Does the use of compression garments increase venous stasis in the common femoral vein? Plast Reconstr Surg 2015;135:85e-91e.

Cheung K, Hume P, Maxwell L. Delayed onset muscle soreness : treatment strategies and performance factors. Sports Med 2003;33:145-164.

Clarkson PM, Hoffman EP, Zambraski E, Gordish-Dressman H, Kearns A, Hubal M, Harmon B, Devaney JM. ACTN3 and MLCK genotype associations with exertional muscle damage. J Appl Physiol (1985) 2005;99:564-569

Cochrane DJ. Effectiveness of using wearable vibration therapy to alleviate muscle soreness. Eur J Appl Physiol 2017;117:501-509.

Driller MW, Halson SL. The effects of wearing lower body compression garments during a cycling performance test. Int J Sports Physiol Perform 2013;8:300-306.

Duffield R, Portus M. Comparison of three types of full-body compression garments on throwing and repeat-sprint performance in cricket players. Br J Sports Med 2007;41:409-414.

Evans WJ, Meredith CN, Cannon JG, Dinarello CA, Frontera WR, Hughes VA, Jones BH, Knuttgen HG. Metabolic changes following eccentric exercise in trained and untrained men. J Appl Physiol (1985) 1986;61: $1864-1868$

Fonseca LB, Brito CJ, Silva RJ, Silva-Grigoletto ME, da Silva WM Junior, Franchini E. Use of Cold-Water Immersion to Reduce Muscle Damage and Delayed-Onset Muscle Soreness and Preserve Muscle Power in Jiu-Jitsu Athletes. J Athl Train 2016;51:540-549.

Fulford J, Eston RG, Rowlands AV, Davies RC. Assessment of magnetic resonance techniques to measure muscle damage $24 \mathrm{~h}$ after eccentric exercise. Scand J Med Sci Sports 2015;25:e28-39.

Goto K, Mizuno S, Mori A. Efficacy of wearing compression garments during post-exercise period after two repeated bouts of strenuous exercise: a randomized crossover design in healthy, active males. Sports Med Open 2017;3:25

Goto K, Morishima T. Compression garment promotes muscular strength recovery after resistance exercise. Med Sci Sports Exerc 2014;46:22652270.

Gottrand L, Devinck F, Martinot Duquennoy V, Guerreschi P. Contribution of the physical and rehabilitation medicine in pediatric plastic surgery. Ann Chir Plast Esthet 2016;61:589-597.

Hill J, Howatson G, van Someren K, Leeder J, Pedlar C. Compression garments and recovery from exercise-induced muscle damage: a meta-analysis. Br J Sports Med 2014;48:1340-1346.

Hirose L, Nosaka K, Newton M, Laveder A, Kano M, Peake J, Suzuki K. Changes in inflammatory mediators following eccentric exercise of the elbow flexors. Exerc Immunol Rev 2004;10:75-90.

Jakeman JR, Byrne C, Eston RG. Lower limb compression garment improves recovery from exercise-induced muscle damage in young, active females. Eur J Appl Physiol 2010;109:1137-1144.

Jamurtas AZ, Theocharis V, Tofas T, Tsiokanos A, Yfanti C, Paschalis V, Koutedakis Y, Nosaka K. Comparison between leg and arm eccentric exercises of the same relative intensity on indices of muscle damage. Eur J Appl Physiol 2005;95:179-185.

Kim J, Lee J. A review of nutritional intervention on delayed onset muscle soreness. Part I. J Exerc Rehabil 2014;10:349-356.

Kraemer WJ, Bush JA, Wickham RB, Denegar CR, Gómez AL, Gotshalk LA, Duncan ND, Volek JS, Putukian M, Sebastianelli WJ. Influence of compression therapy on symptoms following soft tissue injury from maximal eccentric exercise. J Orthop Sports Phys Ther 2001;31:282290.

Lieber RL, Friden J. Morphologic and mechanical basis of delayed-onset muscle soreness. J Am Acad Orthop Surg 2002;10:67-73.

MacRae BA, Cotter JD, Laing RM. Compression garments and exercise: garment considerations, physiology and performance. Sports Med 2011;41:815-843.

Peake J, Nosaka K, Suzuki K. Characterization of inflammatory responses to eccentric exercise in humans. Exerc Immunol Rev 2005;11:64-85.

Petrofsky J, Berk L, Bains G, Khowailed IA, Lee H, Laymon M. The Efficacy of Sustained Heat Treatment on Delayed-Onset Muscle Soreness. Clin J Sport Med 2017;27:329-337.

Serinken MA, Gençoğlu C, Kayatekin BM. The effect of eccentric exercise-induced delayed-onset muscle soreness on positioning sense and shooting percentage in wheelchair basketball players. Balkan Med J 2013;30:382-386.

Smith LL. Acute inflammation: the underlying mechanism in delayed onset muscle soreness? Med Sci Sports Exerc 1991;23:542-551.

Urakawa S, Takamoto K, Nakamura T, Sakai S, Matsuda T, Taguchi T, Mizumura K, Ono T, Nishijo H. Manual therapy ameliorates delayed-onset muscle soreness and alters muscle metabolites in rats. Physiol Rep 2015 Feb 22;3(2). pii: e12279. doi: 10.14814/phy2.12279.

Valle X, Til L, Drobnic F, Turmo A, Montoro JB, Valero O, Artells R. Compression garments to prevent delayed onset muscle soreness in soccer players. Muscles Ligaments Tendons J 2014;3:295-302. 